\title{
ENSINO EM BIOSSEGURANÇA: EDUCAÇÃO E SENSIBILIZAÇÃO DO PROFISSIONAL DE BIOTÉRIO PARA AS PRÁTICAS SEGURAS DE EXPERIMENTAÇÃO ANIMAL
}

\section{TEACHING BIOSAFETY: EDUCATION AND PROFESSIONAL CONSCIOUSNESS OF THE ANIMAL HOUSE WORKER TO SAFETY PRACTICES IN ANIMAL FACILITIES}

\author{
Mariza Angela de Araújo Frisso ${ }^{1}$ e Bernardo Elias Corrêa Soares ${ }^{2}$ \\ ${ }^{1}$ Centro de Criação de Animais de Laboratório e Programa de Pós-Graduação Instituto de Pesquisa \\ Clínica Evandro Chagas - Fundação Oswaldo Cruz. mariza@ fiocruz.br \\ 2 Núcleo de Biossegurança /Departamento de Saúde e Saneamento Ambiental /Escola Nacional de Saúde \\ Pública Sérgio Arouca /Fundação Oswaldo Cruz. \\ Avenida Brasil 4365 - Manguinhos CEP: 21040-360 - Rio de Janeiro \\ bernardo@fiocruz.br
}

\section{Resumo}

O estudo analisa o conhecimento das concepções de risco e segurança, de ex-alunos de cursos de bioterismo e experimentação animal. Após realização de pesquisa bibliográfica e leitura de conteúdo dos materiais existentes sobre o tema, discute-se o interesse do ensino de Biossegurança para os profissionais de saúde , em especial para os aplicados aos estudos com a experimentação e criação animal. Exemplos de risco e medidas preventivas são apresentadas pelos discentes durante o curso, através de seminários específicos. A relação entre tais práticas preventivas e a experimentação animal é também sublinhada, considerando a disciplina da Biossegurança fundamental para garantir a qualidade necessária à execução das tarefas e formulação de diagnósticos e exames no biotério. É fundamental a conscientização e educação permanente dos profissionais, proporcionando-lhes condições para um trabalho seguro, bem como a oportunidade para reflexões, discussões críticas, atualização e adoção de medidas preventivas corretas.

Palavras-Chave: Biossegurança, Riscos, Experimentação Animal, Saúde Pública.

\begin{abstract}
The present paper assays perception and concepts of risk and safety of alumni from courses of animal experimentation or animal house techniques. After thorough bibliographic search and reading of topic literature, the relevance of teaching Biosafety to health professionals is debated, mainly to those applied to animal breeding and maintenance of animal facilities. Examples of risk and preventive measures are given by the students during the course, through specific seminars. Interdisciplinary themes related to Biosafety are also pointed out, considering safety as an essential topic to assure the accomplishment of basic tasks and diagnosis or exams at the animal house. Continued education and capacity building of all professionals is absolutely needed, as well as consciousness on safety rules that may give them better working conditions and a chance to think, criticize and adopt correct safe practices . Biosafety is then placed within a scenario that deals with occupational hazards and their prevention as a tool for protection of life whatever the work performed or the work environment pertaining to it
\end{abstract}

Key-Words: Biosafety, Risks, Animal House, Public Health 


\section{INTRODUÇÃ̃O}

O termo Biossegurança está relacionado à segurança da vida e envolve um conjunto de condições e práticas direcionadas para a prevenção, minimização ou eliminação de riscos inerentes às atividades de produção ensino e pesquisa. "Biossegurança é a condição de segurança alcançada por um conjunto de ações destinadas a prevenir, controlar, reduzir ou eliminar riscos inerentes às atividades que possam comprometer à saúde humana, animal, vegetal e o meio ambiente" (BRASILMinistério da Saúde, 2006). Também para VALLE \& BARREIRA (2007), a Biossegurança é entendida atualmente através dos procedimentos com a manipulação do Ácido Desoxirribonucléico (DNA) e as conseqüências deixadas à saúde humana e ambiental e envolvimento de pesquisas com célula tronco.

Ainda para (COSTA \& COSTA, 2006) a Biossegurança está relacionada com os agravos gerados pelos agentes químicos, físicos, biológicos, ergonômicos e psicossociais, em ambientes ocupacionais do campo da saúde e laboratorial em geral.

Hoje, diversas unidades de pesquisa públicas e privadas estão envolvidas no ensino da Biossegurança, seja no âmbito escolar ou de graduação e pós-graduação, nos estudos clínicos ou na criação de animais. A preocupação com riscos biológicos surgiu a partir da constatação dos agravos à saúde dos profissionais que exerciam atividades em laboratórios onde se dava a manipulação com microrganismos e material clínico desde o início dos anos 40 (PIKE, 1976).

Na década de setenta o foco de atenção voltava-se para a saúde do trabalhador frente aos riscos biológicos no ambiente ocupacional. Para profissionais que atuam na área clínica, entretanto, somente a partir da epidemia da Síndrome da Doença Imunológica Adquirida (AIDS) nos anos 80, as normas para as questões de segurança no ambiente de trabalho foram mais bem estabelecidas.

$\mathrm{O}$ primeiro conceito de Biossegurança se refere às precauções recomendadas para o manuseio de sangue e fluidos corporais, incluindo principalmente a manipulação cuidadosa de instrumentos perfurantes e cortantes contaminados com materiais biológicos, pois estes seriam capazes de transmitir o HIV. Preocupado com a transmissão desses patógenos, o Centers for Disease Control and Prevention (CDC, 1999) publicou as recomendações para prevenção da transmissão do HIV e de outros patógenos veiculados pelo sangue em estabelecimentos de assistência à saúde, e recomendou a utilização das precauções universais, atualmente denominadas precauções padrão, como medida de prevenção para esse tipo de exposição (BRASIL- 
Ministério da Saúde, 2006).

De acordo com a Norma Regulamentadora $n^{\circ}$ 06/78 do Ministério do Trabalho, a empresa é obrigada a fornecer os Equipamentos de Proteção Individual (EPI) aos empregados gratuitamente, adequadamente às situações de riscos e em perfeito estado de conservação e funcionamento. Em contrapartida, a mesma Norma Regulamentadora obriga o trabalhador a usar EPI adequado para a finalidade a que se destina (BRASILMinistério do Trabalho, 1978).

Há então no país duas vertentes para aplicação da Biossegurança: a Legal, que trata das questões envolvendo a manipulação de DNA e pesquisa com células tronco embrionárias, e que tem uma Lei, a de Número 11.105, chamada "Lei de Biossegurança", sancionada pelo governo brasileiro em 24 de março de 2005, e a segunda vertente que é aquela desenvolvida, principalmente nas instituições de saúde, e que envolve os riscos por agentes químicos, físicos, biológicos, ergonômicos, de acidentes e psicossociais, presentes nestes ambientes; esta se reveste de grande importância, principalmente no campo da educação profissional em saúde considerando as interfaces ideológicas,sociais, políticas e econômicas, que perpassam as práticas clínicas e laboratoriais (COSTA, 2006).

A adoção de normas de Biossegurança no trabalho em saúde é condição fundamental para a segurança dos trabalhadores, qualquer que seja a área de atuação, pois os riscos estão sempre presentes. Entre estes riscos estão, por exemplo, a contaminação pelo HIV e hepatite $\mathrm{B}$, que pode ser ainda mais alarmante quando nenhuma medida profilática é adotada.

Sabe-se que o fator de prevenção mais importante é a atitude que cada indivíduo adota, graças a um processo educativo, pois, segundo NICHIATA et al. (2004) a própria equipe de trabalho tem dificuldade em aderir às medidas de segurança que busquem a proteção ao risco de exposição, subestimando, muitas vezes, o próprio risco. Avaliando este fato, é importante nos perguntarmos como está sendo realizada a formação destes profissionais e qual o treinamento recebido nas instituições de saúde sobre a temática em estudo.

O pessoal que trabalha em uma instituição hospitalar entra, com relativa frequencia, na rotina em suas atividades, a tal ponto que, sem se dar conta, vai aumentando sua confiança em relação às áreas e às manipulações de materiais ou pessoas que afluem ao hospital e facilmente omitem procedimentos elementares, como a lavagem das mãos e o uso de luvas, por exemplo. Uma vez que a educação em 
Biossegurança não foi inserida nas disposições legais de formação dos profissionais, existe uma deficiência na formação profissional no que diz respeito a sua sensibilização para medidas práticas de prevenção.

Os riscos presentes no ambiente de trabalho desses profissionais podem afetar a saúde de seres humanos e de animais - para os que trabalham em biotério - e causar danos ambientais, além de comprometer a qualidade do trabalho. Para os profissionais que atuam em biotério, durante a realização de experimentos é necessário: manipular o animal, coletar amostras de tecidos, realizar exames, inoculações e necropsias. Animais podem provocar ferimentos e doenças, bem como escapar e disseminar contaminações no meio ambiente. A manutenção de animais em biotérios envolve trabalho rígido de manejo e higienização rotineira do ambiente onde vivem, se alimentam, produzem dejetos e aerossóis, amplificando os riscos de agravos à saúde.

Por essas razões, todo profissional envolvido com experimentação animal deve estar devidamente informado e capacitado para desenvolver esta atividade.

Nos anos 90, a definição de Biossegurança sofre mudanças significativas e a partir desta década, são incluídos outros fatores no conceito de Biossegurança. Em seminário realizado no Instituto Pasteur, em Paris (INSERM 1991), temas como ética em pesquisa, meio ambiente e trabalhos com animais foram incorporados à Biossegurança e os processos envolvendo tecnologia do DNA recombinante também ficaram fortalecidos nessa discussão.

Foi nesse período que a própria Organização Mundial de Saúde - OMS (WHO, 1993) incorporou a essa definição os chamados riscos periféricos, presentes em ambientes laboratoriais que trabalhavam com agentes de risco para o homem, como os químicos, físicos, (entre eles o ergonômico) e de acidentes.

Em 1996, uma nova definição de Biossegurança foi publicada, que salientou a importância do controle de infecção hospitalar e da orientação aos profissionais para o cuidado no contato com os fluidos corporais, secreções, excreções, pele não-íntegra e mucosas dos pacientes (COSTA \& COSTA, 2006).

No Brasil, a Biossegurança, como campo específico do conhecimento, estruturase a partir de meados da década de 1970. Mas, desde a institucionalização das escolas médicas e da ciência experimental, entre os séculos XIX e XX, vêm sendo construídas noções sobre os riscos inerentes à realização do trabalho científico com diferentes percepções sobre quais os riscos inerentes às atividades do setor saúde. 


\section{METODOLOGIA}

O presente estudo foi realizado através do método da observação. "Método em que o observador participa da vida diária das pessoas em estudo, tanto abertamente no papel de pesquisador, como assumindo papéis disfarçados, observando fatos que acontecem,escutando o que é dito e questionando as pessoas ao longo de um período de tempo (BECKER \& GEER apud TRAUTH \& O`CONNOR, 2000).

No referido trabalho, verificou-se a assimilação dos alunos de um curso de capacitação em Bioterismo, da Fundação Oswaldo Cruz na cidade do Rio de Janeiro, Brasil, quanto à aplicação das normas de Biossegurança em relação ao uso de EPI durante a realização das aulas práticas de laboratório. A população deste estudo foi constituída por alunos do Curso de Desenvolvimento Profissional em Bioterismo, que é oferecido anualmente pelo Centro de Criação de Animais de Laboratórios, onde os discentes convivem em uma mesma sala de aula com diferentes níveis de escolaridade, desde o elementar até a titulação de doutorado.

Para a coleta de dados, o pesquisador utilizou um sistema de anotações em fichas elaboradas para esta finalidade; estas fichas foram os instrumentos utilizados para avaliar os discentes quanto à assimilação dos saberes básicos do ensino de Biossegurança e sobre a utilização de Equipamentos de Proteção Individual (EPI).

As anotações ocorreram nas aulas práticas, no laboratório de controle da qualidade e no período compreendido de 2002 a 2004, oitenta (80) alunos de ambos os sexos foram avaliados, sem que esses discentes soubessem que estavam sendo observados.

Como observado no gráfico 1, dentre os oitenta (80) alunos analisados, cinqüenta e dois (52) eram do sexo masculino com idades compreendidas entre vinte (20) anos e sessenta e quatro (64) anos, enquanto vinte e oito (28) eram do sexo feminino, na faixa etária variante dos vinte e dois (22) aos cinqüenta e nove (59) anos de idade. Ambos os sexos apresentaram interesse na área do Bioterismo. 


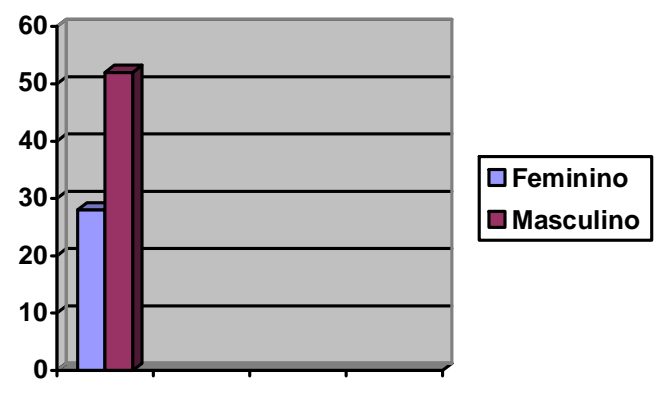

Gráfico 1: Gênero da amostra analisada

Durante este estudo, observou-se que dentre os oitenta (80) discentes, um total de dez (10) discentes não utilizou devidamente os EPI, sendo cinco (5) do sexo masculino com idades variando entre os trinta e oito e sessenta anos, e cinco (5) discentes do sexo feminino, com idades variando entre os trinta e três e cinqüenta e nove anos.

\section{EDUCAÇÃO EM BIOSSEGURANÇA NA FORMAÇÃO PROFISSIONAL}

A inclusão dos conteúdos de segurança, higiene e saúde no trabalho nos currículos escolares devem ser alcançadas em vários níveis de ensino, tendo em vista uma cultura de prevenção no quadro geral do sistema educativo. Porém, a ausência ou limitada presença de educação para a prevenção em nossa sociedade, nomeadamente no sistema educativo e, sobretudo para a população jovem recém-chegada ao mercado de emprego, têm contribuído, de certa forma, para a alta cifra de 370.000 acidentes de trabalho por ano no Brasil (RAMOS \& SILVA, 2009).

MASTROENI (2008) apresenta estimativas divulgadas através de um site sobre riscos biológicos criado por pesquisadores da área da saúde, onde estatísticas de um sistema de vigilância operando desde 2002 apontam para um total de 2.675 acidentes registrados, sendo $24 \%$ ocorridos com estudantes e estagiários. Ainda 80,6\% dos acidentes ocorreram através da exposição percutânea, sendo que 80,7\% tiveram o sangue como veículo de transmissão, sendo as mãos a área corporal mais atingida em torno de $73,3 \%$.

Tal fato sugere a necessidade de uma melhor preparação desses trabalhadores em segurança, higiene e saúde no trabalho, de forma a adquirirem informação técnica, 
comportamentos e atitudes para a prevenção dos riscos que encontram no exercício da sua atividade. Nesta perspectiva, constitui prioridades a sensibilização do meio escolar para a prevenção de riscos profissionais e a integração de conteúdos de segurança, higiene e saúde do trabalho nos currículos dos diferentes níveis de ensino, nomeadamente nos cursos de preparação para a vida ativa (cursos tecnológicos e cursos profissionais).

Há pelo menos duas décadas na educação que a Constituição Federal através do artigo 205 trouxe o desenvolvimento da pessoa, na prática da cidadania e na educação para o trabalho. ARAÚJO (2002) comenta que o Projeto de Lei $\mathrm{n}^{\circ} 1603 / 96$, a respeito da educação, deva atingir uma dimensão tecnológica, científica e comportamental, onde o aluno, faça, crie e eduque-se permanentemente. Todavia (FRISSO, 2005) afirma que o Curso Técnico em Bioterismo, tem então o compromisso de formar esses discentes da forma mais próxima possível das realidades exigidas pelo mercado de trabalho.

Entende-se que esta abordagem constitui um imperativo para a melhoria da qualidade das condições de vida e de trabalho, numa sociedade em que o paradigma emergente para uma nova organização do trabalho, na óptica da prevenção de riscos profissionais, terá, na educação e formação para a prevenção a sua expressão mais estruturante, tendente à integração participativa dos trabalhadores.

Por outro lado, as instituições de saúde pública brasileiras, dentre outros problemas, vêm constatando elevação nas taxas de doenças ocupacionais e acidentes de trabalho, o que, provavelmente está relacionado à não qualificação de seus profissionais em questões de Biossegurança (ROCHA \& FARTES 2001). Neste sentido, autores já citam e atribuem importância à educação permanente para mudança de atitude e, consequentemente, de comportamento, salientando ser indispensável que os profissionais relacionem o risco de acidentes às práticas cotidianas e apontando a necessidade de criar uma cultura de Biossegurança (COSTA \& COSTA, 2006; SOARES,2008).

Os processos de capacitação devem refletir a articulação de conceitos, procedimentos e valores, portanto, os conteúdos da Biossegurança ministrados em cursos de nível médio da área de saúde devem possibilitar ao aluno uma visão integrada e interdisciplinar desses fatores, o que ocorre através da prática docente (AUGUSTO et al., 2004).

Para os profissionais que já se encontram no mercado de trabalho, e não têm tempo e recursos financeiros para se qualificar, cabe às instituições de saúde promover 
atividades de capacitação para que esses profissionais tenham acesso a técnicas e conhecimentos de Biossegurança que lhes permitirão exercer suas funções de maneira mais segura (AMARAL et al., 2005).

A literatura relata que o manejo adequado dos acidentes com material biológico vem tendo, em todo o mundo, um importante papel na redução da taxa de infecção e na maior conscientização dos profissionais da área de saúde. No entanto, é importante ressaltar que as medidas pós-exposição não são totalmente eficazes quanto aos riscos, sendo necessário manter ações educativas permanentes. Por esta razão, do ponto de vista da sensibilização e da habilitação técnica para a prática profissional na área da saúde, ações de promoção à saúde e intervenções de proteção específica em relação aos acidentes com materiais biológicos precisam ser difundidas (ALCÂNTARA et al, 2003).

\section{RISCOS OCUPACIONAIS}

Entre os determinantes da saúde do trabalhador estão compreendidos os condicionantes sociais, econômicos, tecnológicos e organizacionais responsáveis pelas condições de vida e os fatores de risco ocupacionais - físicos, químicos, biológicos, ergonômicos e de acidentes. Assim, as ações de saúde do trabalhador têm como foco as mudanças nos processos de trabalho que contemplem as relações saúde-trabalho em toda a sua complexidade, por meio de uma atuação multiprofissional, interdisciplinar e intersetorial.

No campo da saúde, no qual encontramos profissionais de nível básico, médio e superior com os mais diversos perfis, a inclusão da temática Biossegurança torna-se bastante complexa. A inserção da Biossegurança nesses ambientes, notadamente nos hospitais, laboratórios de saúde pública (LACEN), hemocentros, clínicas veterinárias, universidades, e laboratórios de análises clínicas, entre outros, ocorre de forma bastante diferenciada (COSTA, 2006).

De acordo com a Resolução $287 / 98$ do Conselho Nacional de Saúde, as seguintes áreas são consideradas de saúde: biologia, biomedicina, educação física, enfermagem, farmácia, fisioterapia, fonoaudiologia, medicina, medicina veterinária, nutrição, odontologia, psicologia, serviço social e terapia ocupacional (BRASILConselho Nacional de Saúde, 1998) 
O reconhecimento de situações perigosas é um aspecto subjetivo que depende da percepção e experiência prévia de cada indivíduo. Por esse motivo, é extremamente necessária a criação de um programa eficiente de gerenciamento de risco em unidades de saúde, laboratórios de pesquisa, diagnóstico ou produção. No entanto, depende de uma análise inicial do risco que cada atividade impõe ao trabalhador. $\mathrm{O}$ dimensionamento e gravidade dos riscos servem de argumento técnico para a intervenção e estabelecimento de medidas preventivas. A análise de risco referente à exposição ao agente biológico deve considerar as características infecciosas do agente, assim como a natureza e função da unidade de saúde ou laboratório, os procedimentos e a manipulação do organismo e os aspectos referentes ao próprio trabalhador.

Neste sentido, o profissional de saúde deve desenvolver um senso de responsabilidade com relação à sua própria segurança e à segurança do ambiente de trabalho. Para tal, é necessário obter conhecimentos específicos acerca de como podem ocorrer os acidentes de trabalho, bem como ser responsável pela manutenção da segurança do ambiente através de ações educativas (AMARAL et al., 2005).

\section{BIOSSEGURANÇA EM BIOTÉRIOS DE CRIAÇÃO E A EXPERIMENTAÇÃo ANIMAL}

Em todo o mundo, animais contribuem de forma inequívoca para a melhoria da qualidade de vida, sendo amplamente utilizados em pesquisas para o desenvolvimento de novas tecnologias, vacinas e fármacos, além da geração de conhecimento sobre a biologia das espécies e a interação com o meio ambiente (SARMENTO, 2005). Entretanto, o trabalho com animais sadios, infectados e/ou geneticamente modificados (AGM) expõe médicos veterinários, pesquisadores e técnicos a diversos riscos associados às atividades desenvolvidas em laboratórios de contenção e também em pesquisas de campo.

Por esse fato, ao longo da evolução científica e tecnológica a necessidade de realizar pesquisas com animais e manipular agentes patogênicos levou a comunidade científica a desenvolver um tipo de laboratório ou recinto especial, o biotério de experimentação ou laboratório de experimentação animal, com o intuito de: manter a saúde e o bem-estar dos animais dentro de padrões de excelência, determinando maior confiabilidade aos resultados experimentais; proporcionar a segurança da equipe envolvida no trabalho; assegurar a preservação do meio ambiente, evitando a saída de 
agentes de risco (CDC, 1999).

No biotério de experimentação, onde os animais ficam alojados durante um determinado período experimental, a prática tem demonstrado a conveniência de que esta construção seja próxima à do laboratório de pesquisa. Ter-se-á, portanto, uma construção em torno da qual existam laboratórios e assim, deverão ser previstos espaços para a instalação de barreiras sanitárias de proteção, tanto para o trabalhador quanto para o meio ambiente. Preconiza-se a instalação do biotério de criação em áreas isoladas, distantes de centros urbanos, em locais onde possa ser mais facilmente evitada uma introdução de fatores ambientais desfavoráveis, assegurando-se o cumprimento das normas adequadas de transporte dos animais (CARDOSO, 2000).

No Brasil, entretanto, ainda hoje não existe uma legislação que efetivamente regulamente a utilização de animais para fins didáticos e de pesquisa. Esta lacuna interfere de forma incisiva na conduta ética dos profissionais envolvidos em experimentação e atinge, ainda, o próprio bem-estar dos animais. Segue valendo, apesar de não ter sido devidamente implementada a Lei Federal $\mathrm{N}^{\circ} 6638$, de 08 de maio de 1979, que estabelece normas para a prática didático-científica da vivissecação de animais (PAIVA, MAFLI \& SANTOS, 2005) e a proposta de métodos alternativos a essa pratica.

Sabe-se também que os animais de laboratório representam um risco para quem os maneja, independentemente de estarem ou não infectados, pois podem carrear agentes patogênicos, inclusive zoonóticos, exceto os animais Specif Pathogen Free (S.P.F). Todas as pessoas envolvidas no trabalho com estes animais devem ter consciência deste risco. Sendo assim, as barreiras sanitárias são imprescindíveis nos biotérios de criação e manutenção/experimentação. Portanto, quanto mais eficientes forem as barreiras sanitárias dos biotérios, menores serão as chances de contaminação dos animais.

O manejo de animais oferece aos humanos, basicamente, dois tipos de risco: o de infecção e o traumático (CARDOSO, 2000). As barreiras sanitárias são definidas como mecanismos físicos, químicos e biológicos que dificultam ou minimizam os efeitos da interação entre agentes biológicos de risco com o homem e o animal e que são necessárias, de acordo com o grau de risco do agente envolvido. Como exemplos mencionam-se os materiais utilizados na construção dos biotérios, equipamentos para filtração de ar, autoclaves, higiene pessoal da equipe de funcionários do setor e dos usuários de animais, pressão diferencial entre ambientes e compostos químicos 
utilizados em desinfecção e esterilização.

Os níveis de Biossegurança (NB), para o trabalho com animais vertebrados são designados em ordem crescente como (NB-A) 1, 2, 3 e 4, de acordo com o grupo de risco dos agentes biológicos manipulados, em associação com características e complexidade das instalações, equipamentos de segurança e aplicação de práticas recomendáveis para contenção de riscos. Em relação ao nível de segurança, conforme apresentado por POLITI, PIETRO \& SALGADO (2008), temos:

Nível de Biossegurança Animal 1 (NB-A 1) - Oferece baixo risco individual e comunitário e deve ser utilizado no ensino básico. Não é necessário nenhum tipo de desenho especial, além do atendimento às boas práticas laboratoriais e de um planejamento eficaz, sendo apropriado para a manutenção da maioria dos estoques de animais após a quarentena e, os que são inoculados com agentes classe de risco 1.

Nível de Biossegurança Animal 2 (NB-A 2) - Oferece moderado risco individual e comunitário, podendo causar patologias ao homem ou ao animal. São aqueles que manipulam animais infectados com agentes biológicos da classe de risco 2 . Nestes, o atendimento das boas práticas laboratoriais está somado a alguns requisitos físicos de construção. Os laboratórios níveis 1 e 2 são considerados laboratórios básicos de experimentação animal.

Nível de Biossegurança Animal 3 (NB-A 3) - Oferece risco individual elevado e risco comunitário baixo. O laboratório de experimentação animal de contenção, Nível de Biossegurança Animal 3 (NB-A 3), requer desenho e construção mais especializados que aqueles de níveis 1 e 2. Neste nível de Biossegurança, os técnicos deverão receber treinamentos específicos quanto ao manuseio seguro destes agentes biológicos.

Nível de Biossegurança Animal 4 (NB-A 4) - Oferece elevado risco individual e comunitário. No laboratório de experimentação animal de contenção máxima, as atividades estão diretamente relacionadas às atividades do laboratório de contenção máxima. Só deverão funcionar sob o controle direto das autoridades sanitárias e, devido ao alto grau de complexidade das atividades, recomenda-se elaboração de manual de procedimento de trabalho testado previamente por exercícios de treinamento.

Entre os acidentes que geralmente ocorrem em biotérios, estão: ferimentos causados por animais (arranhão, mordedura, etc.); cortes causados pelas gaiolas, tampas ou outro material; quedas causadas por pisos escorregadios ou degraus; torções causadas por objetos pesados, levantados incorretamente; ferimentos nos olhos e pele, quando da utilização incorreta dos Equipamentos de Proteção Individual. 
Existem ainda os riscos ambientais nos biotérios, que são: a) Físicos - ruídos, temperatura, luminosidade; b) Químicos - poeiras, gases, vapores; c) Biológicos agentes patogênicos (bactérias, fungos, helmintos, protozoários, etc.); d) Acidentesequipamentos, ligações elétricas e ferramentas; e) Ergonômicos - trabalho exaustivo, postura incorreta, levantamento de pesos, etc.

Por conta desses riscos, tanto os funcionários do biotério como pesquisadores e visitantes autorizados devem fazer uso de equipamentos de proteção individual (EPI) ao entrar ou trabalhar em recintos de animais. Os EPI devem ser descontaminados e/ou descartados após o uso segundo critérios estabelecidos de acordo com o risco biológico requerido. Cuidados especiais devem ser observados em unidades onde são mantidas primatas não humanos e animais silvestres, espécies em que o potencial zoonótico é alto ou não está ainda estabelecido. Entre esses cuidados estão: a quarentena de animais; o uso de EPI - como protetores faciais e respiradores com filtros; controle de saúde, testes sorológico; exames clínicos e laboratoriais regulares para diagnóstico e; quando não houver indicação, imunização contra raiva, tétano e hepatite (ANDRADE, PINTO \& OLIVEIRA, 2002).

\section{DISCUSSÃO}

Acredita-se que a implantação de uma adequada política de Biossegurança numa unidade de saúde se inicia com a sensibilização dos profissionais, para que eles se conscientizem da importância do conhecimento do trabalho que realizam, bem como percebam os riscos físicos, químicos e/ou biológicos a que estão expostos no seu dia a dia. Uma vez os riscos sendo conhecidos, os profissionais podem minimizá-los, estabelecendo assim, uma rotina mais segura para, seu ambiente de trabalho e para o meio ambiente. Para a minimização dos riscos, deve ser incluída na rotina destes profissionais a correta utilização de equipamentos de proteção individual e coletiva.

Neste sentido, é necessário o gerenciamento dos riscos, que consiste na adoção de medidas preventivas para a sua minimização e se relaciona com o controle da qualidade no atendimento ou atividade desempenhada. Cabe às comissões (CIBios ) treinar e sensibilizar a sua comunidade à adequação das rotinas às normas de segurança, utilizando-se de incentivos tais como menção, premiação ou uso da legislação para fazer valer medidas operacionais para minimização de riscos e controle de acidentes.

Infere-se que a falta de sensibilização e conscientização, a inadequada supervisão contínua e sistemática da prática, a não percepção individual do risco e a 
falta de educação continuada são fatores associados à ocorrência de acidentes de trabalho com material perfurocortante (AMARAL, 2005). Isso ocorre por que os acidentes de trabalho com os profissionais da área de saúde estão relacionados a questões de ordem pessoal, como desatenção, pressa e despreparo, na maioria das vezes associadas a fatores provenientes das condições de trabalho oferecidas.

Os investimentos institucionais em programas educacionais nas áreas de Biossegurança, cuidados e manejo de animais e ética em pesquisa possibilitam a capacitação e treinamento sistemático, que é fator essencial na promoção da saúde e qualidade das ações.

Para CARDOSO (2007), os princípios das boas práticas, os conceitos da garantia da qualidade, as legislações, as recomendações de Biossegurança e o manejo de animais de laboratório representam portanto, uma etapa fundamental para o estabelecimento da qualidade, reprodutibilidade e confiabilidade nos experimentos realizados em qualquer biotério.

\section{CONSIDERAÇÕES FINAIS}

No que diz respeito à Biossegurança no contexto da formação profissional em saúde, este trabalho mostra a sua extrema importância, tendo em vista a inserção dos seus conteúdos em todos os processos de trabalho pertinentes a esse ambiente ocupacional, fazendo com que o trabalhador não seja um mero reprodutor, mas sim um agente participativo-transformador no seu ambiente ocupacional e na própria sociedade como um todo.

É importante colocar a Biossegurança em um cenário que permita aos profissionais atuarem com prevenção e controle de riscos ocupacionais, entendendo seus propósitos, suas contradições e, principalmente, sua importância como instrumento de proteção da vida, qualquer que seja o ambiente de trabalho.

Levando em consideração a alta rotatividade dos conhecimentos aplicados, a área de Biossegurança, exige das instituições formadoras ações educativas que propiciem, àqueles que se inserem no mercado de trabalho, condições de realizarem suas atividades de forma não apenas tecnicamente adequada, mas também, e principalmente, com domínio crítico e cientes das implicações éticas, ideológicas, políticas e econômicas que perpassam a Biossegurança.

Em um país que já alcançou determinado nível de excelência e reconhecimento 
internacional no que diz respeito à qualidade das pesquisas científicas, torna-se urgente a necessidade de buscar alternativas para melhorar as condições de instalação e funcionamento dos biotérios. Tendo como metas principais, de acordo com o abordado neste artigo, buscar a qualificação de profissionais na manipulação dos animais (pesquisadores, veterinários, zootecnistas, técnicos de biotério, assistentes, etc.) com o desenvolvimento de um programa nacional de capacitação de recursos humanos em bioterismo, padronização das normas e procedimentos de manipulação dos animais e implantação de normas de Biossegurança.

\section{REFERÊNCIAS}

ALCÂNTARA, C.C.S., FONSECA F.G.C., ALBUQUERQUE A.B.B., RAMOS JR. AN. Riscos ocupacionais na atenção primária à saúde: susceptibilidade às doenças imunopreveníveis dos profissionais que atuam em uma unidade básica de saúde de Fortaleza. Ceará. 2005. Revista da APS, Juiz de Fora, v.8, n. 2, p 143-149, 2005.

AMARAL, A.S.; SOUSA A.F.S.; RIBEIRO S.O.; OLIVEIRA M.A.N. Acidentes com material perfurocortante entre profissionais de saúde em hospital privado de Vitória da Conquista. Sitientibus, n.33, p. 101-114, jul./dez. 2005;

ANDRADE, A., PINTO S.C., OLIVEIRA, R.S. (orgs.). Animais de laboratório: criação e experimentação. $1^{\text {a }}$ ed. Rio de Janeiro: Editora Fiocruz. 2002.

ARAÚJO, J. O Público e o público não estável na Nova Ordem. Uma discussão sobre a oferta de serviços socioambientais em estabelecimento educacionais agrícolas. Dissertação de Mestrado apresentada no Instituto de Geociências da Universidade Federal Fluminense. Niterói: UFF. 2002.

ARAÚJO, J. \& FRISSO, M.A. Ensino Técnico Como Forma de Promoção Social: O Curso de Desenvolvimento Profissional em Bioterismo da Fiocruz. Brasil: Editora Fiocruz. 2005.

AUGUSTO, T.G.S., CALDEIRA, A.M.A., CALUZI, J.J., NARDI, R.Interdisciplinaridade: concepções de professores da área ciências da natureza em formação em serviço. Rev Ci Educ.10(2): p. 277-289, 2004.

BRASIL .Ministério do Trabalho. Norma Regulamentadora $n^{\circ}$ 06/78 do Ministério do Trabalho. Brasília. Ministério o Trabalho, 1978.

BRASIL. Conselho Nacional de Saúde. Resolução No 287/98 D.O.U de 08. 10. 98. Brasília: Ministério da Saúde; 1998.

BRASIL. Ministério da Saúde .Secretaria de Ação em Saúde. Departamento 
de Ações Programáticas Estratégicas. Exposição a Materiais Biológicos. Brasília: 2006.

BRASIL. Lei Federal no 11.105, de 24 de março de 2005. Brasília: MCT, 2005.

CARDOSO, T.A.O. Programa arquitetônico de biotérios. In: TEIXEIRA, P, org. Curso de aperfeiçoamento em Biossegurança. 1 $^{\mathrm{a}}$ ed. Rio de Janeiro: EAD/ 2000.

CARDOSO, T.A.O. A Ciência entre Bichos e Grilos reflexões e ações da Biossegurança com animais. $1^{\mathrm{a}}$ ed. São Paulo: Editora Hucitec. 2007.

CDC - CENTERS FOR DISEASE CONTROL AND PREVENTION Biosafety.in microbiological and biomedical laboratories. 4 ed.Washington Writer Ed. GA. 1999.

COSTA, M.A.F; COSTA, M.F.B. Biossegurança: elo estratégico de segurança e de saúde no trabalho. Revista CIPA, São Paulo, v.266, p. 86-90, 2002.

COSTA, M.A.F. Construção do conhecimento em saúde: o ensino de Biossegurança em cursos de nível médio na Fundação Oswaldo Cruz. Tese de doutorado Instituto Oswaldo Cruz: Rio de Janeiro: 2006.

COSTA, M.A.F.; COSTA. M.F.B. Entendendo a Biossegurança: epistemologia e competências para a área da saúde. $1^{\mathrm{a}}$ ed. . Rio de Janeiro: Ed. Publit, 2006.

COSTA, M.A.F.; COSTA, M.F.B. Ensino de ciências em saúde: contribuições para a inserção da Biossegurança na formação profissional. Encontro nacional de ensino de ciências da saúde e do ambiente. ISBN 978-85-99661-03-UNIPLI, 15-17 de maio 2008.

FRISSO, M.A. Por uma nova proposta teórico metodológica para a disciplina de controle bacteriológico. Dissertação de Mestrado Universidade Plínio Leite. Rio de Janeiro, 2005.

INSERM. Les Risques Biologiques en Laboratoire de Recherche. Institut Nationale de Sciences et Études de Recherche Médicale. Paris 1991.

MASTROENI, M. F. Biossegurança aplicada a laboratórios e serviços de saúde, Ed. Atheneu, 2008.

NICHIATA LYI, G.I.R. E, TAKAHASHI, RF, CIOSAK, S.I. Evolução dos isolamentos em doenças transmissíveis: os saberes na prática contemporânea. Revista da Escola de Enfermagem US; 38 (1): 61-70.2004.

PAIVA ,F.P., MAFFLI ,V.V., SANTOS , A.C.S. Curso de manipulação de animais de laboratório. Fundação Oswaldo Cruz (FIOCRUZ). Centro de Pesquisas Gonçalo Muniz. Salvador. Salvador: Editora Fiocruz. 2005.

PIKE, R.M. Laboratory-associated infections: Summary and analysis of 3,921 cases Heaith Lab Sci. 13:105-114, 1976.

POLITI, F.A.Z ; PIETRO, C.L.R., SALGADO, H.R.N. Caracterização de biotérios, legislação e padrões de biossegurança. Revista de Ciências Farmacêuticas Básica 
e Aplicada, Vol. 29, $\mathrm{n}^{\mathrm{o}}$ 1. 2008.

RAMOS, F.A.; SILVA, S.A.P. Segurança e bem estar no trabalho. Monografia apresentada ao Curso de Graduação em Administração da FACECAP/CNEC para obtenção do título de bacharel em administração CAPIVARI - SP, 2009.

ROCHA, S,S.; FARTES ,V.L..B. Biossegurança e competência profissional: um novo desafio para a educação no setor saúde. Caderno $C R H$, vol. 34, p. 125-140 jan./jun. 2001.

SARMENTO, E.O. Biossegurança e Experimentação Animal. Revista CFMV Brasília/DF -Ano XI - N 36. Set-Dez 2005.

SOARES, B. E.C. Prevenção de Riscos Biológicos para os profissionais de Saúde e Perspectiva de Biossegurança. Revista Infecto Atual; Ano IX. Edição 50. Abril/Maio 2008.

TRAUTH, E. M.; O CONNOR, B. A. study of the interaction between information technology and society: and illustration of combined qualitative research methods. Disponível em <http://www.cba.new.edu/ etrauth/works/fip5.td>. Acesso em: 18, novembro de 2010.

VALLE, S ;BARREIRA,Y.(Orgs.). Biossegurança-Engenharia Genética; Legislação Brasileira. Rio de Janeiro: Publit, 2007.

WHO-WORLD HEALTH ORGANIZATION. Laboratory Biosafety Manual. $2^{\text {nd }}$. Geneve: WHO, 1993. 